\title{
Accelerating research to business with Hilla Runway model
}

\section{Jarkko Hyysalo*, Jaakko Sauvola and Jukka Riekki}

Faculty of Information Technology and Electrical Engineering, University of Oulu, Oulu, Finland

Email: jarkko.hyysalo@oulu.fi

Email: jaakko.sauvola@oulu.fi

Email: jukka.riekki@oulu.fi

* Corresponding author

\begin{abstract}
The key to win on global markets is not based only on excellence of products and services, but increasingly more on successful business models and value networks, where partnering, smart specialisation and joint solution deliveries are the key elements for sustainable success. There also has to be solid processes and tools for facilitating the transfer from research to business the creation and evolution of business. Hilla Runway provides a model and a toolset that supports business development and commercialisation.
\end{abstract}

Keywords: business; inter-enterprise collaboration; research to business; value co-creation; innovation; commercialisation.

Reference to this paper should be made as follows: Hyysalo, J., Sauvola, J. and Riekki, J. (xxxx) 'Accelerating research to business with Hilla Runway model', Int. J. Technology Transfer and Commercialisation, Vol. X, No. Y, pp.xxxxxx.

Biographical notes: Jarkko Hyysalo is a Postdoctoral Researcher in the Faculty of Information Technology and Electrical Engineering at the University of Oulu. His research interests include software architectures and processes, IoT, and collaborative work. He received his $\mathrm{PhD}$ in Information Processing Science from the University of Oulu.

Jaakko Sauvola is Professor of data-intensive systems and advanced software at the University of Oulu and leader of Finland's High-Tech ICT Leverage from Long-Term Assetization (HILLA) Program. His research interests include mobility, system architectures, and data-intensive services and analytics. $\mathrm{He}$ received his $\mathrm{PhD}$ in Technology from the University of Oulu.

Jukka Riekki is Professor of software architectures for embedded systems and Dean of the Faculty of Information Technology and Electrical Engineering at the University of Oulu, and Principal Investigator in the university's Center of Ubiquitous Computing. His research interests include interactive, context-aware systems that support everyday tasks and edge computing driven by the IoT. He received his $\mathrm{PhD}$ in Technology from the University of Oulu. $\mathrm{He}$ is a member of IEEE. 


\section{Introduction}

Product development is a set of activities starting with the perception of a market opportunity and ending in the production, sales, and delivery of a product (Ulrich and Eppinger, 2015). Understanding and identifying repeatable design and business processes in product development are the keys to repeatable success. Providing a portfolio of tools and processes for research commercialisation would greatly benefit both the organisations and the society at large.

However, several challenges can be identified. For example, in Finland the companies are often too limited in their scope or too small to compete for larger commercial deals regarding international clients. The commercialisation results are poor in the UK and Europe as well (Ruiz, 2010). A common issue for contemporary businesses is that value chains are not working as they were. Also the clock-cycle of the competitive environment is intensifying rapidly. The lifecycle of products and services is decreasing and the international competition - in particular, in the area of digitalised solutions - is evermore tougher. In this environment, the problem is to transfer innovations quickly into commercialisable solutions. The side effect is time: the more complex, regulated or fragmented is the industry and its business(es), the more time these preparations need.

To address this very problem, and to create new wealth for companies we have developed a Hilla Runway model that facilitates the effective utilisation of the potential of digitalisation, accelerates the research to business (R2B) process, and supports the smart specialisation.

\section{Commercialising research}

Commercialising research is crucial part of the innovation process because without commercialisation, the innovation has little value to society or wider economy (Zhao, 2004). Research commercialisation is also a challenging task, e.g., despite the high amount of research and number of published scientific papers in the UK, the commercialisation results are still poor, which is also the case in Europe (Ruiz, 2010). Similarly, in Finland, the amount of engineers and researchers, as well as the R\&D investments, is very high, but in the last 10-15 years, there have not been considerable export-driven ICT efforts to replace the now dismantled Nokia mobile phone cluster. Innovations emerge, but there is no business. Hence, there is a real need to support research commercialisation. However, the meaning of research commercialisation is vague in literature (Zhao, 2004) and process models for that are scarce as well. The commercialisation process can be examined from several perspectives like innovation, technology and knowledge transfer, and relationships and dynamics between various actors.

Technological innovation is a complex process. Several processes are available for those activities, like open innovation. Open innovation has strong focus on inter-firm cooperation in R\&D (Ruiz, 2010). In open innovation, organisations' internal R\&D is integrated with external ideas and technologies, combining different assets and competencies, and commercialisation is often done within an innovation community instead of a single organisation (Lynn et al., 1996). Ideas and technologies are researched, selected, developed and commercialised with the inflows and outflows of technology and knowledge at different stages - knowledge outside the organisation is 
valuable and beneficial. However, an open innovation process is not trivial to implement. There are challenges with the processes, organisations' willingness to open their processes to others, and in the capability to manage the multiple collaborations (Ruiz, 2010). Furthermore, there are surprisingly few open knowledge flows between research organisations and industry (Van de Ven, 2007).

Technology transfer is a form of knowledge transfer aiming at research commercialisation. It can take many forms, e.g., university to university, university to business, large business to small business, government to business, across borders, and in formal/informal way. The aim is to benefit both research and business and to create new value as the new technology is put into use. Successful technology transfer benefits the universities and creates jobs for local economy (Mehta, 2004). Nonetheless, the effort of commercialisation is not trivial, especially for SMEs. Therefore, various intermediary organisations like technology transfer offices (TTOs) exist to help in the commercialisation of new knowledge. Different models are also available to help and study this effort, like Triple Helix model, which is an internationally recognised model that focuses on understanding and explaining the university-industry-government relationship, and how universities convert their knowledge into value (Davey, 2017).

Relationships also play an important role in research commercialisation. Dana et al. (2008) suggests symbiotic entrepreneurship where independent organisations operate together, each bringing their own expertise in order to increase their overall efficiency and profit. In general, the quality of relationships facilitates the value creation (Kothandaraman and Wilson, 2001). Strong linkage between the research organisations and the industry is a success factor; respectively, the need for an intermediary is greater when that relationship is not that strong in the first place (Suvinen et al., 2010). For example, the lack of a proper linkage is the major bottleneck in research commercialisation in universities (Zhao, 2004).

When organisations commercialise their research results, intermediary organisations are useful bridging the gap between science and industry. The intermediaries' aid for commercialising the new knowledge, e.g., by diminishing the market and system failures and tackling the challenges that may rise, is of utmost importance.

Intermediaries may also provide direct commercialisation support, help in networking different actors and facilitating the interactions (Suvinen et al., 2010; Howells, 2006). However, not many studies have investigated the intermediaries' role in commercialisation, instead, focusing on the results and effectiveness of the commercialisation activities (Suvinen et al., 2010; Bozeman, 2000). Furthermore, the importance of intermediary organisations in research commercialisation is hard to measure, since the effects are often indirect (Suvinen et al., 2010; Bozeman, 2000).

\subsection{The need for a new growth model in Finland}

Finland is in an unprecedented situation after the Finnish mobile device business crash 2011-2014:

1 ICT experts are laid-off in thousands

2 the largest market channel and revenue stream is lost

3 ecosystem around mobile devices is lost 
4 Nokia consumer brand benefits are lost

5 very few internationally savvy ICT companies

6 Nokia devices R\&D contribution to Finnish ICT is lost.

However, there are also positive effects that facilitate a change - a reboot of the Finnish digital network:

1 Nokia Bridge program to support new start-up creation is successful

2 several capable, but small firms

3 digitalisation is spreading quickly in many businesses

4 existing ICT executive network with understanding about scaling

5 new technologies and business models entering the arena

6 top-notch technology know-how and appetite to succeed.

While the benefits of commercialisation are obvious to industry, the benefits are considerable also for universities. Besides financial benefits, the reputation of the university is improved both nationally and internationally (Zhao, 2004). However, as the topic of commercialising the university research is a considerably new phenomenon, especially in Finland, the practices are not well established yet and there is lack of, e.g., intermediary services, like incubator services or programs (Suvinen et al., 2010). Hence, a need is rising for organisations, approaches, models and tools for supporting the commercialisation of research. Hilla (http://www.hilla.center) provides a way to address these very needs. Hilla is a publicly funded programme focusing on networking and facilitation support to further economic growth in Finland. In addition, Hilla also provides the runway model and a toolset to support business development.

\section{Hilla Runway model and tools}

To address the identified needs, we have developed a Hilla Runway. In Hilla Runway, the aim is to set up consortiums that work together in projects of at least three companies and find complementarities between the companies. As the aim is to go to the market in a condensed time, the success requires market presence by one lead company with a presence on key markets already. The consortia provide novel opportunities for agile SMEs and access to key markets. The strong conviction is that structured collaboration between various Finnish actors produces better products and services than isolated actions.

The aim is to have projects large enough for solid research and development work to have a real impact on the businesses, with the research budget around $€ 600,000$ and the corresponding company projects' budgets depending on the business case requirements. The research project of this size means that the research work is in the scale of 4-5 person-years by the research partners. Thus, around a similar amount of work commitment is expected of the company consortia of the project.

The target is commercialisation within 12-18 months. This sets novel requirements also on deep commitment to projects, in which research parties work tightly with companies to apply the latest research to utilise international market potential identified. 
With rapid preparatory work and decision making in an optimal case, the time span from a feasible idea to a funding decision of a sizeable project can be 4-6 months only. To achieve the aims above, Hilla provides companies a full-scale approach and toolset to create differentiating and scalable products, services and businesses to global markets, see Figure 1. This is supported both by world-class research as well as thorough support for business development.

Figure 1 Hilla Runway (see online version for colours)

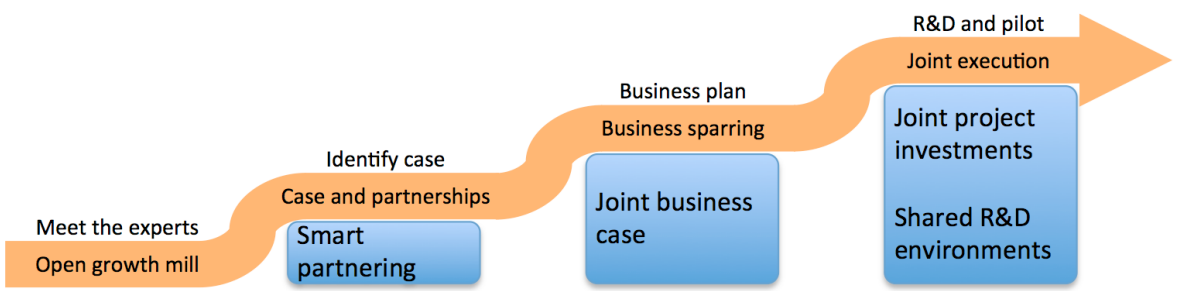

Figure 2 Hilla Runway model for integrating key tools and ways of working for faster research-to-markets (see online version for colours)

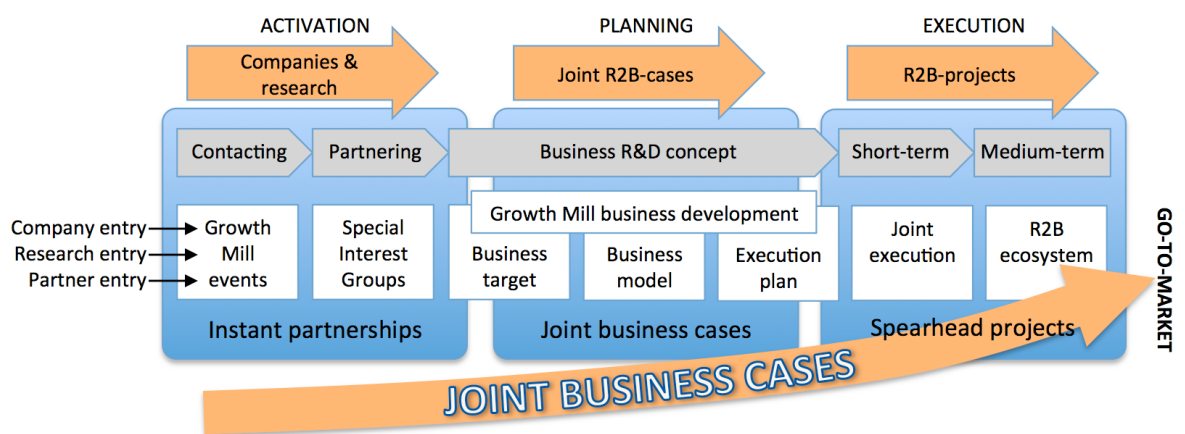

The runway model assists the businesses to go to the market in a condensed time with innovative ICT products and services utilising the latest research. The projects developing the products and services are sparred to have at least one lead company providing the channel for the market, to have complementing competences in the company group and to find the best resources to the research. The model also supports deepening the long-term collaboration between companies and research entities. For a shorter-term value, companies also need to understand new technology and research aspects. Hilla is binding this need to a model, where companies are partnered based on the need in the business, and clear research questions are being solved by research organisations in a target-driven partner model. This in its turn gives an excellent basis for teaming up on co-creation for longer-term value. Companies need a setting where their partners share common vision and excitement and have clear, agreed goals. Thus, Hilla Runway model offers many paths to expand the partnership between companies and research organisation to build a future agenda for research and funding schemes. This way, company-research teams can execute on 'next gen roadmap' research questions within Hilla Enabling Technology Project model. Researchers gain relevant and valuable 
insight into industry problems to renew the basic research agenda, and together with these teams form an excellent basis for winning EU funding, and drive a joint business research agenda, whose contents evolve to a joint strategic project portfolio. The structured approach is summarised in Figure 2.

The runway model contains activation, planning and execution phases. In the activation phase, Growth Mill (GM) builds networks, specifies and coaches projects towards spearhead projects and scalable business. Activation also gathers the profiled companies and creates groups interested in specified business possibilities, i.e., Specialised Interest Groups (SIG) created in Hilla Enabling Concepts (HEC) projects. The planning phase spars the potential business ideas identified by SIGs to spearhead and Enabling Technology Research (ETR) projects with proven market appetite to buy. The spearheads are carefully designed and well-prepared collaborative investments. They are in the strategic core of the company and culmination point of rapid market entries. ETR caters the road for continuous renewal of products and offerings beyond the short-term steps done in the spearhead projects, producing next generation roadmap disruptions. The execution phase in its turn runs the accepted projects and supports also other activities triggered by smart partnering and business case development, e.g., building shared R\&D environment and supporting joint business cases that company groups decide to commercialise without HILLA funding. Smart partnering and joint business cases chain the investments to motivate long-term road-mapped collaboration between companies and research entries.

Other capabilities and tools for technology transfer are Flying TUTLI that offers a unique opportunity for researchers working in spearheads or ETR projects to spin-out their value by joining company research teams. Shared R\&D environments (SREs) offer cutting edge new technologies, tools and facilities as a service to Hilla projects and broader to all companies with ICT leverage needs. Scientist in residence (SiR) increases expert mobility and expedites technology transfer. Companies receive a 'time-share' from top know-how, while research organisations receive direct visibility to industrial needs.

Hilla Funding Services navigate the company-research teams through the funding opportunities, processes and partnering. GM funnel cases are key customers for Hilla Funding Services. RADAR will improve awareness of highest-value emerging key technologies, expediting investment decisions and optimising timing on research and companies with joint business cases.

Hilla supports the market access also with its go-to-market (GTM) work. Its target is to establish a high-performance, agile and visible piloting environment for the spearhead projects' proof-of-concept and customer showcasing at the earliest feasible moment. These pilots offer an environment, where key findings and concepts can be tested and shown to interested customer prospects. Another acceleration effort to the markets is the work with foreign direct investments (FDI). Companies working with Hilla gain a direct runway and a channel to markets via FDI companies and can thus directly gain for foreign investments made to Finland. FDI as a market channel offers a practical landing zone for international companies with partners and ICT research. Local companies gain direct runway and channel to markets via FDI company.

Hilla stands apart from conventional development programs by being company-needdriven and providing its support from idea development towards the execution of targeted, focused projects. In addition, the Hilla service framework provides support for the companies in identifying complementary funding and implementation mechanisms to 
ensure the viability and sustainability of work undertaken. Hilla offers for the companies a variety of integrated tools and services, embedding agile integration, smart specialisation and business case tools with a target to improve R2B efficiency. The Hilla Runway model assists to crystallise the business idea(s) and business logic, facilitate partnerships, discuss novel earning models and formulate ideas for feasible project plans and proposals, including the vital research component.

\section{Hilla Runway experiences}

The Hilla program was started in February 2015 and it has gained positive results already. Hilla has attracted a large amount of companies throughout Finland and many Finnish cities and hubs have been interested to utilise and join the Hilla network. Participants were provided several avenues to meet various experts, to network with leading experts and to utilise their full potential for business. GM events enabled meeting colleagues and developing joint ideas for projects and actions. Companies were encouraged to participate in SIG and even initiate dedicated actions towards potential project ideas in HEC.

In cases where large companies acted as the lead company, the objectives for the project were often quite clear. The Hilla model brought along the breakthrough idea with the smaller companies and latest technology and research capabilities, and challenged the entire team to define their growth plans for the time after the initial project and beyond the lead customer case, i.e., ensuring the scale and growth targets are agreed and understood. Small companies in their turn - who are used to competing for the attention of the larger companies - could in the initial stages of the planning process feel uncomfortable with other SMEs in the project consortium and see much overlapping and competing functions within the other members of the group. The sparring sessions acted as a catalyst to create an open growth business dialog between all companies in the project before the project was initiated. In some cases, this sparring style revealed the incompatibility at early stages, resulting in the spearhead idea to be dropped or original companies to be replaced with more suitable ones.

The initial Hilla model was fine-tuned during the course of the first months, based on

1 feedback from the companies and research parties

2 based on the elevated analysis and adaptation to market realities (the situation of companies revealed in spearhead sparring sessions, the voice of the customer dialogues, requirement analysis of 'what it takes to realise the company plans to growth capturisation').

Market driven 'lead company' - 'specialised company' model was developed and deployed immediately, with promising feedback.

With respect to numeric target setting, Hilla portfolio phases exceeded our expectations. However, the projects are still on the lower end of size range. This is due to 'expert bandwidth' and 'learning curve'; the agile process for preparing the organisations for high-quality projects is new to all parties, and it is estimated to take time to reboot and recreate a new market driven research and business culture. 


\subsection{Evaluation of Hilla Runway}

The Hilla Runway model has been a success and it is showing its power to create new R2B ecosystems. The feedback from participating companies and research organisation has been encouraging. Numerous dialogues and discussions have revealed a great need for a focused model, where value added results from research and companies are merged to new market offerings. The very proof of this is that our first spearhead teams are already launching their new products, perform joint marketing efforts and are in the discussion about deeper alliances.

Hilla is following planned operational excellence indicators. These are being benchmarked during the ongoing renewal of the model, and will undergo continuous improvements as the program model evolves further. The key indicators include most important aspects to build new business spearheads, the partnering for business cases, the research and company investments, the shared assets, network economy advances and the extended funding and investment actions.

In Hilla, the master key performance indicator (KPI) is revenue potential that illustrates the value of all the efforts carried out by Hilla communities and actions. In other words, all actions Hilla is investing need to create value that can be measured in monetary terms. Someone is willing to evaluate the outcomes in terms of paying for it, thus the value is measured and can be tracked back to all Hilla actions. Sub-KPIs obey to master KPI, by contributing to it directly: Spearheads produce revenue potential, the number of companies enables us to find the best partners to join spearheads and other R2B actions, ecosystems focus on customer interfacing activity, where research and company joint research, development and innovation are valued by the markets, Hilla Funding Services KPI in its turn seeks necessary funding for investments needed to serve master KPI, and so on.

Value generation requires partnership with linked interests, partners who are embedded in the local communities of beneficiaries and stakeholders, and structured processes (Austin and Seitanidi, 2012). It is beneficial for small companies to work together with larger ones to create networks with various capabilities (Dana et al., 2008). There are benefits for larger companies also, as small companies may perform specialised functions for larger ones, thus providing flexibility (Dana et al., 2008). In addition, Hilla Runway model encourages the research and business partners to work together, and the effort clearly facilitates the value creation, as shown in Figure 3 summarising the Hilla achievements.

1,700 industry executives entered the Hilla Runway. GM and SIG were the tools for the first phase in Hilla Runway model, where networks were built and business ideas were created and honed. 1,100 companies participated in the GM and 12 SIGs were created, each with their own industry project portfolio. Business cases were developed with 35 ICT projects and estimated revenue $€ 650 \mathrm{M}$. The third phase consisted of R\&D and pilots. Ten approved joint business plans were created in the third phase, and the number of shared R\&D environments was 35 , with $€ 10 \mathrm{M}$ investments from joint efforts of research organisations and companies. Eight company-research ecosystems were created with 400 companies from the domains of internet-of-things (IoT), artificial intelligence, gaming, drones, health, water, printed electronics and $5 \mathrm{G}$ applications. Over 20 commercial company partnerships were agreed upon, and over ten international business-to-business sales deals were arranged through the ecosystem. 
Figure 3 Hilla in numbers (see online version for colours)

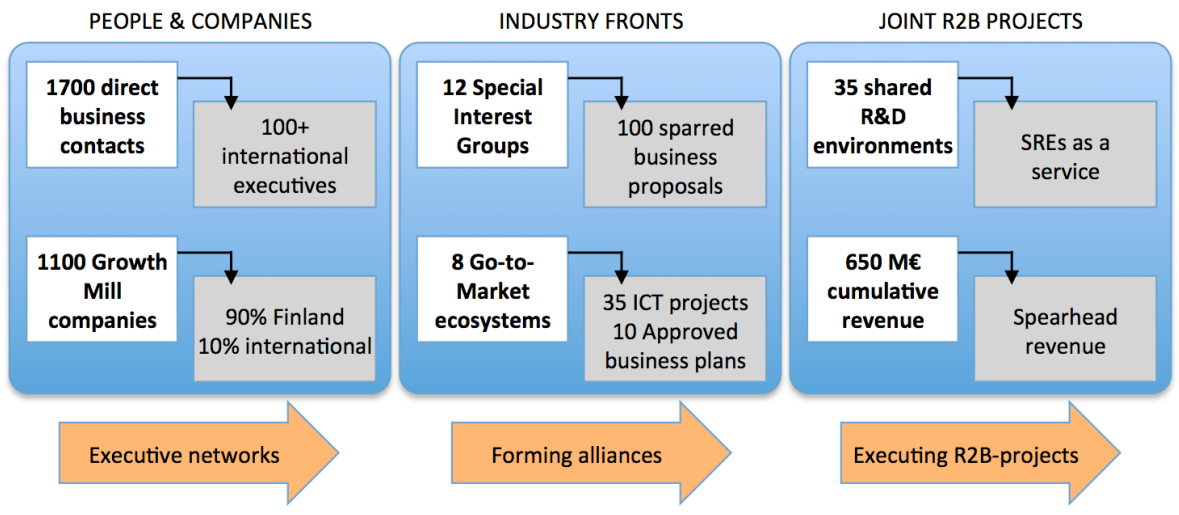

In comparison to other approaches, Hilla Runway seems to provide several qualities that are missing from others. Table 1 summarises important qualities of models supporting R2B transformation. Open innovation, technology transfer/TTOs and intermediary organisations are evaluated based on the literature, while Hilla Runway is evaluated through usage experience and user feedback.

Table 1 Evaluation of R2B models

\begin{tabular}{lcccc}
\hline & $\begin{array}{c}\text { Open } \\
\text { innovation }\end{array}$ & $\begin{array}{c}\text { Technology } \\
\text { transfer/TTOs }\end{array}$ & $\begin{array}{c}\text { Intermediary } \\
\text { organisations }\end{array}$ & $\begin{array}{c}\text { Rilla } \\
\text { Runway }\end{array}$ \\
\hline Partnering and networking & - & - & + & + \\
Idea creation and development & + & - & + & + \\
Commercialisation & + & - & + & + \\
Practices and processes & + & - & - & + \\
Tools & - & - & - & + \\
Research to industry knowledge transfer & - & + & - & + \\
Intermediation & - & + & + & + \\
\hline
\end{tabular}

Note: + - support; - - no support.

- Partnering and networking is considered as important in open innovation; however, open innovation does not explicitly support partnering and networking (Lee et al., 2010). Technology transfer/TTOs do not support partnering and networking, either. On the other hand, intermediaries often provide support for partnering and networking and facilitate collaboration (Suvinen et al., 2010; Howells, 2006), while Hilla Runway provides visibility and support, and acts as a partnering and network creation tool.

- Idea creation and development is supported in open innovation, as it is built upon innovation and developing the ideas further. TTOs do not focus on idea creation or development. Intermediary organisations support innovation and developing of new products and services (Lee et al., 2010), and Hilla Runway provides support and tools for idea creation and development. 
- Commercialisation is supported in open innovation and various business models are considered, even though open innovation is normally more considered on the early stages of innovation (Vanhaverbeke and Cloodt, 2006). TTOs provide some support on commercialisation, however limited and inflexible (Siegel et al., 2003). Intermediaries provide commercialisation support (Suvinen et al., 2010; Howells, 2006), and also Hilla Runway supports and provides tools for commercialisation.

- Practices and processes are considered in open innovation, and some practices and processes are distinguished (Van de Vrande et al., 2009). With TTOs, practices and processes vary and are not explicit (Siegel et al., 2003). With intermediary organisations, the practices and processes are not well defined, either (Suvinen et al., 2010; Howells, 2006). With Hilla Runway, on the other hand, a comprehensive set of practices and processes are available for various purposes.

- Tool support is not explicitly provided in open innovation. Similarly with TTOs, however, tool support depends on the TTO. With intermediary organisations, a need to develop better frameworks and tools is also recognised (Howells, 2006), whereas with Hilla Runway, a complete set of tools for all phases from partnering and idea creation to commercialisation is provided.

- Research to industry knowledge transfer is not explicit in open innovation, and there are only a few open knowledge flows between research and industry (Van de Ven, 2007). TTOs support knowledge and technology transfer (Siegel et al., 2003). Intermediary organisations do not explicitly support knowledge transfer; instead, they help to link organisations to new ideas created elsewhere (Howells, 2006), whereas Hilla Runway supports knowledge and technology transfer with several practices and processes.

- Intermediation is not explicitly provided with open innovation, either; however there are efforts to complement open innovation with intermediaries (Lee et al., 2010). TTOs provide intermediation (Siegel et al., 2003), and intermediary organisations provide intermediation by nature. Hilla also acts as an intermediary.

As a summary, the Hilla Runway differentiates from other models with comprehensive processes and tools that provide companies a fast track from an idea towards international market entry in a condensed time. The innovative products and services developed are based on solid, high quality research. Current other Finnish models are less business driven and do not contain all the required tools, and can thus only partially answer the needs of companies. Comparable international efforts exist, e.g., in Germany, China and USA, and Hilla is partnering with these other centres of excellence to develop its approach, working methods and tools further.

\section{Conclusions}

The Hilla Runway model is effective because it takes into account both technology needs (market pull) and offers (push). For example, the traditional technology transfer focuses on technology push, while open innovation focuses on technology pull. Hilla Runway combines both of these aspects in order to create a balanced mix by matching the 
technology needs and offers, at the same time, creating relationships and facilitating communication between participants.

The Hilla Runway model is gaining healthy traction both from companies and researchers in Finland, but also international companies through various partnering, foreign direct investments and direct channels. Hilla offers a clear path and medium to find partners, match with the best of the latest technologies, the research knowledge and work on joint business cases sparred from the business development perspective towards a business. Especially SME companies have a clear need when many larger businesses are entering the investment, reasoning, e.g., on IoT, 5G, new internet protocols such as block chain and big data based analytics within their products and systems renewal. Further, the industrial Internet and the integration of these elements via new business and operational models are of great interest with a lot of confusion from the business model and offering perspectives that need clarification.

Hilla has gained a lot of positive feedback about tending more of "how things are actually made in commercial and research partnerships that leads directly to the market deployments", instead only of "what is being done in the technology space". Especially international partners have communicated this as a key differentiation of Hilla: Direct partner identification, combined with cutting edge technologies via honest and bold dialogues to produce multi-party commitment to investments.

\section{References}

Austin, J.E. and Seitanidi, M.M (2012) 'Collaborative value creation: a review of partnering between nonprofits and businesses. Part 2: Partnership processes and outcomes', Nonprofit and Voluntary Sector Quarterly, Vol. 41, No. 6, pp.929-968.

Bozeman, B. (2000) 'Technology transfer and public policy: a review of research and theory', Research Policy, Vol. 29, Nos. 4-5, pp.627-655.

Dana, L.P., Etemad, H. and Wright, R.W. (2008) 'Toward a paradigm of symbiotic entrepreneurship', International Journal of Entrepreneurship and Small Business, Vol. 5, No. 2, pp. 109-126.

Davey, T. (2017) 'Converting university knowledge into value: how conceptual frameworks contribute to the understanding of the third mission role of European universities', International Journal of Technology Transfer and Commercialisation, Vol. 15, No. 1, pp.65-96.

Howells, J. (2006) 'Intermediation and the role of intermediaries in innovation', Research Policy, Vol. 35, No. 5, pp.715-728.

Kothandaraman, P. and Wilson, D.T. (2001) 'The future of competition: value-creating networks', Industrial Marketing Management, Vol. 30, No. 4, pp.379-389.

Lee, S., Park, G., Yoon, B., and Park, J. (2010) 'Open innovation in SMEs - an intermediated network model', Research Policy, Vol. 39, No. 2, pp. 290-300.

Lynn, L.H., Reddy, N.M. and Aram, J.D. (1996) 'Linking technology and institutions: the innovation community framework', Research Policy, Vol. 25, No. 1, pp.91-106.

Mehta, S. (2004) 'The emerging role of academia in commercializing innovation', Nature Biotechnology, Vol. 22, No. 1, pp.21-24.

Ruiz, P.P. (2010) Technology \& Knowledge Transfer under the Open Innovation Paradigm, Doctoral dissertation, University of Bath.

Siegel, D.S., Waldman, D. and Link, A. (2003) 'Assessing the impact of organizational practices on the relative productivity of university technology transfer offices: an exploratory study', Research Policy, Vol. 32, No. 1, pp.27-48. 
Suvinen, N., Konttinen, J. and Nieminen, M. (2010) 'How necessary are intermediary organizations in the commercialization of research?', European Planning Studies, Vol. 18, No. 9, pp.1365-1389.

Ulrich, K. and Eppinger, S. (2015) Product Design and Development, McGraw-Hill Education, New York, NY.

Vanhaverbeke, W. and Cloodt, M. (2006) 'Open innovation in value networks', Open Innovation: Researching a New Paradigm, pp. 258-281, Oxford University Press, NY.

Van de Ven, A.H. (2007) Engaged Scholarship: A Guide for Organizational and Social Research, Oxford University Press, Oxford.

Van de Vrande, V., De Jong, J.P., Vanhaverbeke, W. and De Rochemont, M. (2009) 'Open innovation in SMEs: trends, motives and management challenges', Technovation, Vol. 29, Nos. 6-7, pp.423-437.

Zhao, F. (2004) 'Commercialization of research: a case study of Australian universities', Higher Education Research \& Development, Vol. 23, No. 2, pp. 223-236. 